\section{Primary gastric mantle cell lymphoma}

\author{
Duska Petranovic, ${ }^{1}$ Gorazd Pilcic, ${ }^{1}$ \\ Milena Peitl, ${ }^{2}$ Aleksandar Cubranic, ${ }^{1}$ \\ Toni Valkovic, ${ }^{1}$ Antica Duletic Nacinovic, ${ }^{1}$ \\ Ksenija Lucin, ${ }^{3}$ Nives Jonjic ${ }^{3}$ \\ ${ }^{1}$ Department of Internal medicine, \\ University Hospital Center Rijeka; \\ 2Department of Oncology, University \\ Hospital Center Zagreb; ${ }^{3}$ Department \\ of Pathology, Faculty of Medicine, \\ University of Rijeka, Croatia
}

\section{Abstract}

Mantle cell lymphoma represents $2.5-7 \%$ all of non Hodgkin's lymphomas. Stomach is the most common site of extranodal lymphoma. However, that is not the case with mantle cell lymphoma, which is extremely rare. We present a case of 71-year-old woman admitted to the Internal Clinic of the University Clinical Hospital Center Rijeka, because of stomach discomfort and melena. Endoscopy and computed tomography revealed a polyp in gastric antrum. Histopathologic, immunohistochemic and genetic methods were also performed and the results were consistent with primary gastric mantle cell lymphoma without periepigastric and/or local or distant abdominal lymph node involvement.

\section{Introduction}

Primary isolated gastric mantle cell lymphoma (MCL) is an extremely rare form of gastrointestinal tumour. It represents $2.5-7 \%{ }^{1}$ of all non-Hodgkin's lymphomas. However, stomach is the most comon site of extranodal lymphoma, which are almost all of B-cell lineage, including extranodal marginal zone B-cell lymphomas of mucosa-associated lymphoid tissue (MALT lymphoma) and diffuse large B-cell lymphomas (DLBC). ${ }^{2,3}$ Development of MCL is a result of malignant transformation of B-cell lymphocytes in mantle zone of a lymph node follicle - pregerminal center that surrounds normal germinal center follicles. This subtype of non-Hodkin's lymphoma is also caracterized by the chromosomal translocation $\mathrm{t}(11 ; 14)$ (q13;q32). ${ }^{3,4}$ Specific result of this translocation is an overexpression of the cyclin D1 (CCND1), which is normally not expressed in B lymphocytes, who have a very important rolle in cell cycle regulation. Furthermore, immunohistochemical phenotype $\mathrm{CD}^{+}, \mathrm{CD}^{+} 9^{+}$, CD20+, CD10-, CD23-, FMC-7+ ${ }^{+}$bcl-2+ and cyclin $\mathrm{D}^{+}$is specific of MCL. ${ }^{2-6}$ We however need to emphasize that aberrant immunophenotype was also established in several cases. ${ }^{4,7-8}$ Although nowadays we do have powerful genetic, immunohistocemical and other modern diagnostic and therapeutic methods, MCL still presents itself as a very aggressive disease with poor prognosis and median survival of 3-4 years. ${ }^{1}$

The first case of isolated primary MCL has been published in $2004 .{ }^{9}$ Since then very few case reports have been reported and published, and those that were usually were secondary gastric involvements from nodal mantle cell lymphoma (MCL) or lymphomas in the course of primary intestinal MCL (lymphomatous polyposis).

We present a case of gastric MCL in a patient without other gastrointestinal comorbidities and without personal history of significant illnessess (except mild arterial hypertension).

\section{Case Report}

A 71-year-old, previously healthy female patient was admitted at the Internal Clinic of the University Clinical Hospital Center Rijeka, because of persistent stomach discomfort (lasting for 5 months) and melena. Her medical records showed that she had been previously diagnosed only with mild arterial hypertension and had no gastrointestinal symptoms. Physical examination revealed an overweight, pale, cardiorespiratory compensated patient without any palpable peripheral lymph nodes, no liver or spleen enlargement or any pathologic abdominal mass. However, the patient complained of slight discomfort during the palpation of the epigastric region.

Laboratory analyses showed anemia due to iron deficiency (Hemoglobin $94 \mathrm{~g} / \mathrm{L}, \mathrm{MCV} 81 \mathrm{fL}$, MCHC $318 \mathrm{~g} / \mathrm{L}$, Fe 3 umol/L, UIBC $62 \mathrm{umol} / \mathrm{L}$, feritin $16 \mathrm{ug} / \mathrm{L}$ ), with slightly elevated ESR (38 $\mathrm{mm} / \mathrm{h})$. Leukocyte total count was normal $(4,2$ $\left.\times 10^{9} / \mathrm{L}\right)$ with proportional leukocyte differential count. Platelets $\left(357 \times 10^{9} / \mathrm{L}\right)$ and coagulation tests were in normal range as well as other biochemical analyses (proteinogram, CRP and LDH).

Gastroscopy (Figure 1) and computerized tomography (Figure 2) identified a large ulcerated tumor with polypoid surface in the gastric antrum, with no apparent local lymph node involvement.

Histological analysis of tissue taken by gastric biopsy revealed a dense atypical lymphoid infiltrate composed of small to medium sized cells with slightly irregular nuclear contours. Immunohistochemically, cells were positive for CD20, CD5, CD79a, CD43 and cyclin D1, but negative for CD3, and bcl-6 (Figure 3).
Correspondence: Gorazd Pilcic, University Clinical Hospital Center Rijaka, Department of Internal Medicine, Krešimirova 42, 51000 Rijeka, Croatia.

Tel. +385.5165 .8111 - Fax: +385.5165 .8826 .

E-mail: gorazd.pilcic@gmail.com

Key words: primary gastric mantle cell lymphoma, diagnosis, therapy.

Contributions: DP, ADN and TV collected clinical data. AC performed endoscopic examination and biopsy. KL, NJ performed pathological analysis. GP and MP wrote the manuscript.

Conflicts of interest: the authors declare that they have no competing interests.

Received for publication: 25 June 2011.

Revision received: 7 December 2011.

Accepted for publication: 9 December 2011

This work is licensed under a Creative Commons Attribution NonCommercial 3.0 License (CC BYNC 3.0).

(ㄷ) Copyright D. Petranovic et al., 2012

Licensee PAGEPress, Italy

Hematology Reports 2012; 4:e1

doi:10.4081/hr.2012.el

Fluorescent in situ hybridization studies showed the presence of the chromosomal translocation $\mathrm{t}(11 ; 14)(\mathrm{q} 13 ; \mathrm{q} 32)$, which is characteristic for MCL. Extensive clinical staging was performed but no further evidence of lymphoma was established (colonoscopy; computerized tomography of thorax, abdomen and pelvis; bone marrow analysis). Following chemotherapy (8 cycle RCHOP) the patient is disease free at 12 months after diagnosis, confirmed by PET/CT immaging and gastroscopy.

\section{Discussion}

We present a case where MCL is not associated with any other gastrointestinal pathological condition. However, we took into consideration comorbidities often associated with appearance of MCL. MCL is more likely to appear along with other gastrointestinal diseases (Chron's disease, adenocarcinoma). ${ }^{1,2,9}$ In the vast majority of cases, gastrointestinal lymphoma can be diagnosed with endoscopic biopsy. By using additional immunological and molecular markers we can group lymphomas into subtypes according to the WHO classification and that is the cornerstone for further decision making. We retrospectively reviewed clinical features, including involved organs, histopathologic examination, immunohisto- 
chemic and genetic methods. We also established Cyclin D1 overexpression and performed immunohistochemic methods (cells were positive for CD20, CD5, CD79a, CD43 and negative for CD3) which finally confirmated the diagnosis of gastric MCL.

Primary gastrointestinal mantle cell lymphomas are very uncommon and they rarely involve stomach. Contrary to that, stomach is the most common site of primary extranodal lymphoma, although almost all cases are of Bcell lineage. Isolated primary gastric localization is extremely rare. All that being said, mantle cell lymphoma is a specific type of malignant lymphoma that has been reported mostly through case reports. ${ }^{1,9}$ Therefore, the fact that there are only few reported cases limits our understanding of primary mantle cell lymphoma from a clinical and therapeutic viewpoint.

Treatment of MCL is nowhere near satisfac- tory and there are no proven and standard regimes used in therapy. Standard therapy by alkylating agents (with or without corticosteroids) offers substantial palliation but no real cure and treatment therefore fails in majority of cases. Effective treatment of gastric MCL still remains a very controversial issue with very poor response rates. ${ }^{10-12}$

\section{Conclusions}

Primary isolated gastric mantle cell lymphoma (MCL) is an extremely rare form of gastrointestinal tumour. Stomach is the most common site of extranodal lymphoma. To our knowledge, only few authors described the appearance of a primary gastric mantle cell lymphoma. However, in those cases tumor occurence was associated with other gastrointestinal diseases. Therefore, the fact that there are only few reported cases limits our understanding of primary mantle cell lymphoma from a clinical and therapeutic viewpoint. We present a case where MCL was not associated with any other gastrointestinal pathological condition, even though Chron's disease and adenocarcinoma were taken into consideration. Current experiences with treatment of MCL are very poor and there are no proven and standard regimes used in therapy. Effective treatment of gastric MCL still remains a very controversial issue with very poor response rates. Therefore, mantle cell lymphoma has a very poor prognosis. In the light of everything said, one should always consider a primary mantle cell lymphoma if a solitary gastrointestinal polypoid tumor is discovered, especially if no other gastrointestinal diseases are present.

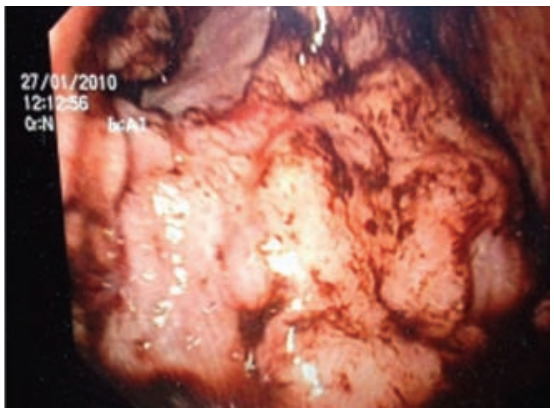

Figure 1. Gastroscopy - tumor presence in the gastric antrum.

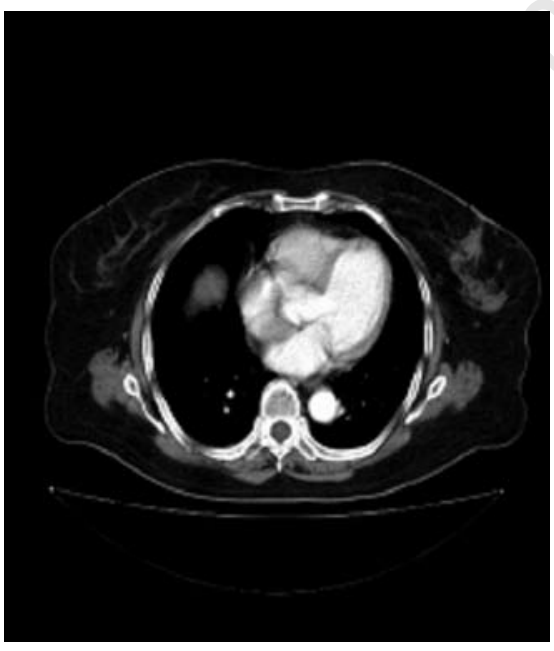

Figure 2. Computerized tomography. Diffuse wall thickening of the gastric antrum, which is in direct contact with the wall of duodenum and suppresses pancreas.
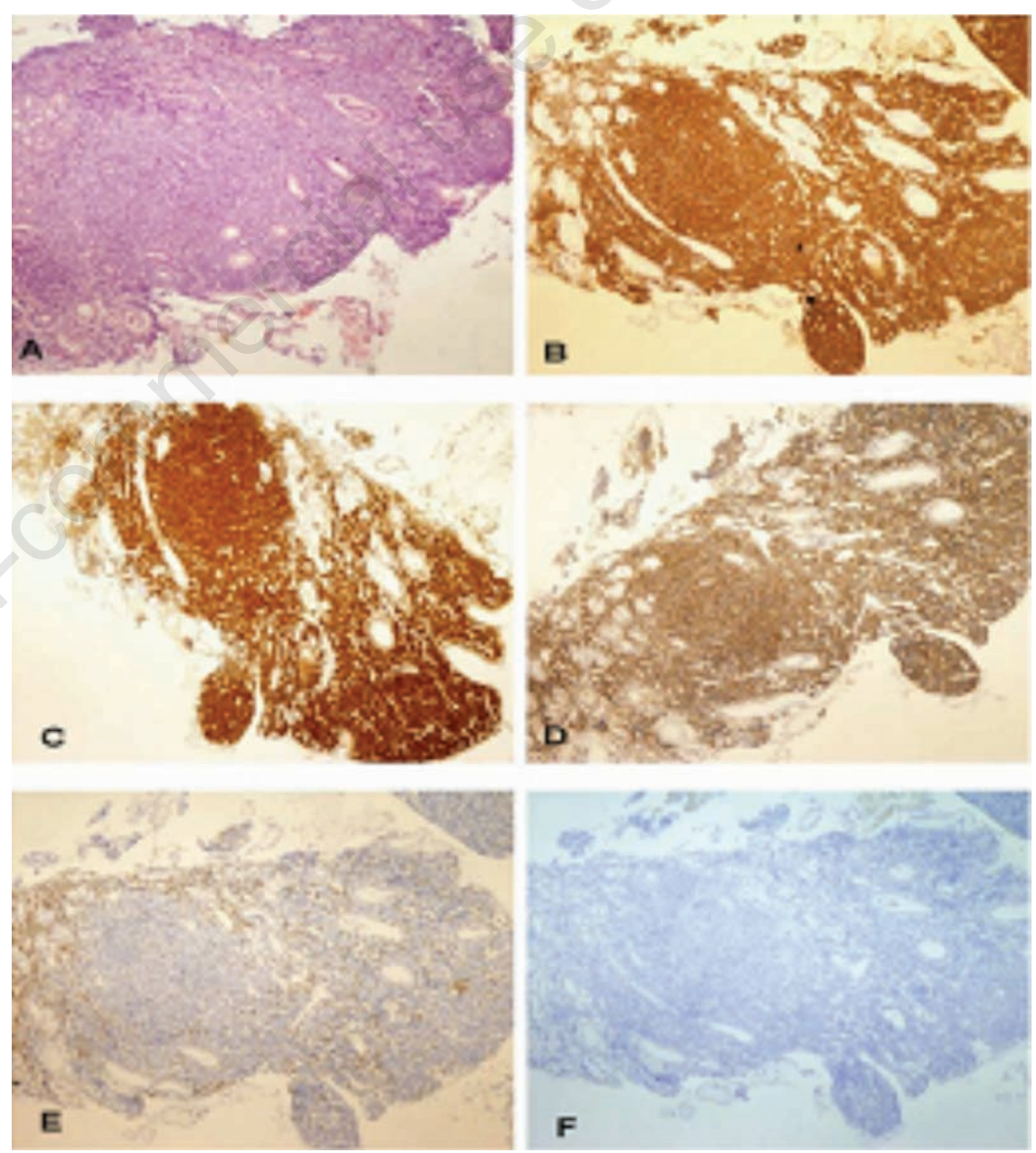

Figure 3. Histological picture of gastric mantle-cell lymphom. Magnification $x$ 40. A) tumor cells show nodular and diffuse infiltration of gastric mucosa; $B$ ), C) and D) tumor cells are positive for $\mathrm{CD20}$, ciklinD1 and $\mathrm{CD} 5$ antigen; $\mathrm{E}$ ) and $\mathrm{F}$ ) tumor cells are negative for CD3 and bcl-6. 


\section{References}

1. Chong Y, Shinn JJ, Cho MY, et al. Synchronous primary gastric mantle cell lymphoma and early gastric carcinoma: a case report. Pathol Res Pract 2008;204: 407-11.

2. Smith MD, Singelton TP, Balaraman S, et al. Case report: mantle cell lymphoma, prolymphocytoid variant, with leukostasis syndrome. Modern Pathology 2004;17:87983.

3. Koch P, del Valle F, Berdel WE, et al. Primary gastrointestinal non-Hodgkin's lymphoma: I. Anatomic and histologic distribution, clinical features, and survival data of 371 patients registered in the German Multicenter Study GIT NHL 01/92. J Clin Oncol 2001;19:3861-73.
4. Camacho FI, Garcia JF, Cigudosa JC, et al. Aberrant Bcl6 protein expression in mantle cell lymphoma. Am J Surg Pathol 2004; 28:1051-6.

5. Yashino T, Omonishi K, Kobayashi K, et al. Clinicopathological features of gastric mucosa associated lymphoid tissue (MALT) lymphomas: high grade transformation and comparison with diffuse large B cell lymphomas without MALT lymphoma features. J Clin Pathol 2000;53:187-90.

6. Chan JK. Gastrointestinal lymphomas: an overview with emphasis on new findings and diagnostic problems. Seminars in Diagnostic Pathology 1996;13:260-96.

7. De Boer CJ, Van Krieken JH, Schuuring E, Kluin PM. Bcl-1/cyclin D1 malignant lymphoma. Ann Oncol 1997;8Suppl2:109-17.

8. Kai F, Weisenburger DD, Greiner TC, et al. Cyclin D1-negative mantle cell lymphoma: a clinicopathologic study based on gene expression profiling. Blood 2005;106:431521.

9. Zapata M, Budnick SD, Bordoni R, Li S. An uncommon case of de novo CD10+ CD5mantle cell lymphoma mimics follicle center B cell lymphoma. Int J Clin Exp Pathol 2010;3:430-6.

10. Raderer M, Püspök A, Birkner T, et al. Primary gastric mantle cell lymphoma in a patient with long standing history of Chron's disease. Leuk Lymphoma 2004;45: 1459-62.

11. Witzig TE. Current treatment approaches for mantle-cell lymphoma. Journal of Clinical Oncology 2005;23:6409-14

12. Lenz G, Dreyling M, Hiddemann W. Mantle cell lymphoma: established therapeutic options and future directions. Ann Hematol 2004;83:71-2. 